37. T. Crook et al., Dev. Neuropsychol. 4, 261 (1986)

38. M. S. Albert, Proc. Natl. Acad. Sci. U.S.A. 93, 13547 (1996); _ and M. B. Moss, in Handbook of Biology of Aging, E. L. Schneider, J. W. Rowe, T. E. Johnson, N. J. Holbrook, J. H. Morrison, Eds. (Academic Press, San Diego, CA, ed. 4, 1996), pp. 217 233; R. Fama et al., Arch. Neurol. 54, 719 (1997); A Convit et al., Neurobiol. Aging 18, 131 (1997); C. R. Jack Jr. et al., Neurology 49, 786 (1997).

39. J. W. Rowe and R. L. Kahn, Science 237, 143 (1987).

40. S. L. Vincent, A. Peters, J. Tigges, Anat. Rec. 223 329 (1989); J. Tigges, J. G. Herndon, A. Peters, Neurobiol. Aging 11, 201 (1990); J. Bachevalier et al., ibid. 12, 99 (1991); A. Peters and C. Sethares, Anat. Rec. 236, 721 (1993); A. Peters, D. Leahu, M. B. Moss, K. J. McNally, Cerebr. Cortex 4, 62 (1994); Y. Geinisman, L. DeToledo-Morrell, F. Morrell, R. E. Heller, Prog. Neurobiol. 45, 223 (1995); P. R. Rapp, in Emotion, Memory and Behavior, T. Nakajima and T. Ono, Eds. (Japan Scientific Societies Press, Tokyo, 1995), pp. 197-211; J. Tigges, J. G. Herndon, D. L. Rosene, Acta Anat. 153, 39 (1995); A. Peters et al., J. Neuropathol. Exp. Neurol. 55, 861 (1996); J. Tigges, J. G. Herndon, D. L. Rosene, Acta Anat. 157, 63 (1996); C. B. Y. Kim L. P. Pier, P. D. Spear, Anat. Rec. 247, 119 (1997)

41. W. T. Greenough, R. W. West, T. J. DeVoogd, Sci ence 202, 1096 (1978); D. G. Flood, S. J. Buell, G. Horwitz, P. D. Coleman, Brain Res. 402, 205 (1987); F. L. F. Chang, K. R. Isaacs, W. T. Greenough, Neurobiol. Aging 12, 517 (1991); L. M. Callahan and P. D. Coleman, ibid. 16, 311 (1995).

42. A. Peters, J. Comp. Neurol. 371, 153 (1996)

43. C. A. Barnes, Trends Neurosci. 17, 13 (1994).

44. and B. J. McNaughton, in Psychobiology of Aging: Problems and Perspectives, D. Stein, Ed. (Elsevier, Amsterdam, 1980), pp. 253-272; D. L. Deupree, D. A. Turner, C. L. Watter, Brain Res. 554 1 (1991); C. I. Moore, M. D. Browning, G. M. Rose, Hippocampus 3, 57 (1993).

45. T. V. P. Bliss and T. Lømo, J. Physiol. (London) 232 331 (1973); R. G. M. Morris, E. Anderton, G. S. Lynch, M. Baudry, Nature 319, 774 (1986); M. Meunier, J. Bachevalier, M. Mishkin, E. A. Murray, J. Neurosci. 13, 5418 (1993); T. V. P. Bliss and G. L. Collingridge, Nature 361, 31 (1993).

46. A. H. Gazzaley, S. J. Siegel, J. H. Kordower, E. J. Mufson, J. H. Morrison, Proc. Natl. Acad. Sci. U.S.A 93, 3121 (1996).

47. M. E. Bach, R. D. Hawkins, M. Osman, E. R. Kandel, M. Mayford, Cell 81, 905 (1995); M. Mayford, J. Wang, E. R. Kandel, T. J. O'Dell, ibid., p. 891; K. Sakimura et al., Nature 373, 151 (1995); T. Abel et al., Cell 88, 615 (1997).

48. For example, see L. S. Higgins, D. M. Holtzman, J. Rabin, W. C. Mobley, B. Cordell, Ann. Neurol. 35 598 (1994); D. Games et al., Nature 373, 523 (1995); L. S. Higgins, J. M. Rodems, R. Catalano D. Quon, B. Cordell, Proc. Natl. Acad. Sci. U.S.A 92, 4402 (1995); E. Masliah et al., J. Neurosci. 16 5795 (1996); M. C. Irizarry et al., ibid. 17, 7053 (1997); M. Jucker and D. K. Ingram, Behav. Brain Res. 85, 1 (1997); J. Nalbantoglu et al., Nature 387 500 (1997)

49. C. S. Woolley and B. S. McEwen, J. Neurosci. 12 2549 (1992); J. Comp. Neurol. 336, 293 (1993); J. Neurosci. 14, 7680 (1994).

50. A. H. Gazzaley, N. G. Weiland, B. S. McEwen, J. H. Morrison, J. Neurosci. 16, 6830 (1996).

51. C. S. Woolley, N. G. Weiland, B. S. McEwen, P. A. Schwartzkroin, ibid. 17, 1848 (1997)

52. H. Fillit et al., Psychoneuroendocrinology 11, 337 (1986); C. Berr, S. Lafont, B. Debuire, J. F. Dartigues, E. E. Beaulieu, Proc. Natl. Acad. Sci. U.S.A 93, 13140 (1996); M. Tang et al., Lancet 348, 429 (1996); "The Role of Ovarian Hormones in Cognition and Dementia," S. J. Birge, Ed., Neurology 48 (suppl. 7), S1 (1997); C. Kawas et al., ibid., p. 1517; J. A. Roberts, K. V. K. Gilardi, B. Lasley, P. R. Rapp, NeuroReport 8, 2047 (1997).

53. Y. Goodman, A. J. Bruce, B. Cheng, M. P. Mattson, J. Neurochem. 66, 1836 (1996).

54. D. C. Sterio, J. Microsc. 134, 127 (1984).

55. R. W. Williams and P. Rakic, J. Comp. Neurol. 278
344 (1988); ibid. 281, 335 (1989); M. J. West, L. Slomianka, H. J. G. Gundersen, Anat. Rec. 231, 482 (1991); M. J. West, Neurobiol. Aging 14, 275 (1993) 56. We thank C. A. Barnes, C. Bouras, A. H. Gazzaley, P. Giannakopoulos, C. V. Mobbs, E. A. Nimchinsky, P. R. Rapp, and J. C. Vickers for their crucial contri- butions and advice, and W. G. M. Janssen, A. P. Leonard, and R. S. Woolley for expert technical assistance. Research in our laboratory was supported by $\mathrm{NIH}$ grants AG05138 and AG06647, the Human Brain Project MHDA52145, the Charles A. Dana Foundation, and the Brookdale Foundation.

\title{
The Endocrinology of Aging
}

\author{
Steven W. J. Lamberts, ${ }^{*}$ Annewieke W. van den Beld, \\ Aart-Jan van der Lely
}

Most aging individuals die from atherosclerosis, cancer, or dementia; but in the oldest old, loss of muscle strength resulting in frailty is the limiting factor for an individual's chances of living an independent life until death. Three hormonal systems show decreasing circulating hormone concentrations during normal aging: (i) estrogen (in menopause) and testosterone (in andropause), (ii) dehydroepiandrosterone and its sulphate (in adrenopause), and (iii) the growth hormone/insulin-like growth factor I axis (in somatopause). Physical changes during aging have been considered physiologic, but there is evidence that some of these changes are related to this decline in hormonal activity. Hormone replacement strategies have been developed, but many of their aspects remain controversial, and increasing blood hormone levels in aging individuals to those found during mid-adult life has not been uniformly proven to be safe and of benefit.

The average length of human life is currently 75 to 78 years and may increase to 85 years during the coming two decades (1), but is not clear whether these additional years will be satisfying to live. Most data indicate a modest gain in the number of healthy years lived but a far greater increase in years of compromised physical, mental, and social function (2). The number of days of restricted activity and the number of admissions to hospitals and nursing homes sharply increases after age 70 (3). One U.S. health interview survey indicates that, at present, more than 25 million aging people suffer from physical impairment, whereas the number of people requiring assistance with activities of daily living increases from $14 \%$ at age 65 to 75 to $45 \%$ in those over 85 years old (4).

\section{Aging and Physical Frailty}

Throughout adult life, all physiological functions gradually decline (5). There is a diminished capacity for cellular protein synthesis, a decline in immune function, an increase in fat mass, a loss of muscle mass and strength, and a decrease in bone mineral density (5). Most elderly individuals will die from atherosclerosis, cancer, or dementia; but in an increasing number of the

The authors are in the Department of Medicine, Erasmus University, Rotterdam, Netherlands.

*To whom correspondence should be addressed at the Department of Medicine, University Hospital Dijkzigt, 40 Dr. Molewaterplein, 3015 GD Rotterdam, Netherlands. E-mail: lamberts@inw3.azr.n healthy oldest old, loss of muscle strength is the limiting factor that determines their chances of living an independent life until death.

Age-related disability is characterized by generalized weakness, impaired mobility and balance, and poor endurance. In the oldest old, this state is called physical frailty, which is defined as "a state of reduced physiological reserves associated with increased susceptibility to disability" (6). Clinical correlates of physical frailty include falls, fractures, impairment in activities of daily living, and loss of independence; falls contribute to $40 \%$ of admissions to nursing homes (7).

Loss of muscle strength is an important factor in the process of frailty. Muscle weakness can be caused by aging of muscle fibers and their innervation, osteoarthritis, and chronic debilitating diseases (8). However, a sedentary lifestyle and decreased physical activity and disuse are also important determinants of the decline in muscle strength. In a study of 100 frail nursing home residents (average age 87 years), lower-extremity muscle mass and strength were closely related (9). Supervised resistance exercise training (for 45 min three times per week for 10 weeks) doubled muscle strength and significantly increased gait velocity and stair-climbing power. This demonstrates that frailty in the elderly is not an irreversible effect of aging and disease but can be reduced and perhaps even prevented (9). Also, among nondisabled elderly people living in the 
community, objective measures of lowerextremity function are highly predictive of subsequent disability (10). In a study we conducted, the leg extensor power of 400 elderly, independently living men varied widely (Fig. 1). Prevention of frailty can be achieved only by exercise. However, exercise is difficult to implement in the daily routine of the aging population, and the number of dropouts from exercise programs is very high (11).

Part of the aging process affecting body composition (loss of muscle size and strength, loss of bone, and increase in fat mass) might also be related to changes in the endocrine system $(5,12)$. Here we analyze recent knowledge about the effects of long-term hormonal replacement therapy on body composition as well as on atherosclerosis, cancer formation, and cognitive function.

\section{Endocrinology of Aging}

The two clinically most important changes in endocrine activity during aging involve the pancreas and the thyroid. Approximately $40 \%$ of individuals 65 to 74 years old and $50 \%$ of individuals older than 80 years have impaired glucose tolerance or diabetes mellitus, and nearly half of elderly diabetics are undiagnosed $(13,14)$. These persons are at risk of developing secondary, mainly macrovascular, complications at an accelerated rate (15). Pancreatic, insulin receptor, and post-receptor changes associated with aging are critical components of the endocrinology of aging: Apart from decreased (relative) insulin secretion by the $\beta$ cells, peripheral insulin resistance related to poor diet, physical inactivity, increased abdominal fat mass, and decreased lean body mass contribute to the deterioration of glucose metabolism $(15,16)$. Dietary management, exercise, oral hypoglycemic

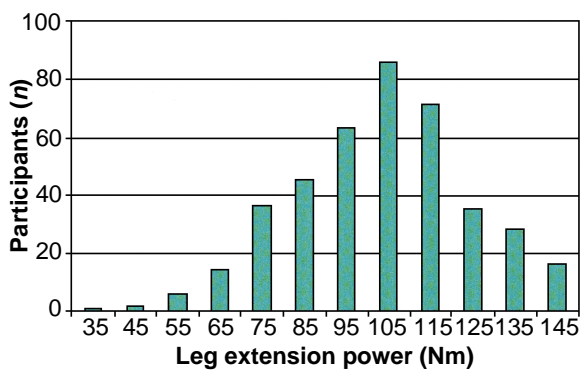

Fig. 1. Muscle strength, as measured by maximum leg extensor power, in 400 healthy, independently living, elderly men (mean age, 78 years; age range, 73 to 94 years). The maximum value of three measurements of both legs is shown. A Hoggan microFET hand-held dynamometer was used for the measurements (64). agents, and insulin are the four components of treatment of these patients, whose medical care is costly and intensive (17).

Age-related thyroid dysfunction is also common in the elderly (18). Lowered plasma thyroxine $\left(\mathrm{T}_{4}\right)$ and increased thyrotropinstimulating hormone (TSH) concentrations occur in 5 to $10 \%$ of elderly women (18). These abnormalities are mainly caused by autoimmunity and are therefore an expression of age-associated disease rather than a consequence of the aging process $(19,20)$. Normal aging is accompanied by a slight decrease in pituitary TSH release (18), but especially by a decreased peripheral degradation of $\mathrm{T}_{4}$, which results in a gradual agedependent decline in serum triiodothyronine $\left(\mathrm{T}_{3}\right)$ concentration, without an important change in $\mathrm{T}_{4}$ levels (21). This slight decrease in plasma $\mathrm{T}_{3}$ concentration occurs largely within the broad normal range of the healthy elderly population and has not been convincingly related to functional changes during the aging process (18). At present, the question of whether healthy aging people might benefit from $\mathrm{T}_{3}$ replacement therapy remains uninvestigated.

The changes in insulin sensitivity and thyroid function that occur in the aging population are frequently of clinical importance and are recognized and treated as diseases. Three other hormonal systems show decreasing circulating hormone concentrations during normal aging, and these changes have been considered mainly physiologic (Figs. 2 and 3). In recent years, hormone replacement strategies have been developed, but many of their aspects remain controversial, and increasing hormone blood levels to those found in 30- to 50-year-old individuals has not yet been uniformly proven to be safe and of benefit.

The most dramatic and rapidly occurring change in women around the age of 50 is menopause (22). Cycling estradiol $\left(E_{2}\right)$ production during the reproductive years is replaced by very low, constant $E_{2}$. For many years, the prevailing view was that menopause resulted from an exhaustion of ovarian follicles. An alternative perspective is that age-related changes in the central nervous system and the hypothalamo-pituitary unit initiate the menopausal transition. The evidence that both the ovary and the brain are key pacemakers in menopause is compelling (23). Changes in the activity of the hypothalamo-pituitary-gonadal axis in males are slower and more subtle. During aging, a gradual decline in serum total and free testosterone (T) levels occurs (24). This "andropause" is characterized by a decrease in testicular Leydig cell numbers
Fig. 2. During aging, a decline in the activities of a number of hormonal systems occurs. (Left) A decrease in GH release by the pituitary gland causes a decrease in the production of IGF-I by the liver and other organs (somatopause). (Middle) A decrease in release of gonadotropin luteinizing hormone $(\mathrm{LH})$ and follicle-stimulating hormone $(\mathrm{FSH})$, together with a decreased secretion at the gonadal level (from the ovaries, decreased $\mathrm{E}_{2}$; from the testicle, decreased T), cause menopause and andropause, respectively. (Right) The adrenocortical cells responsible for the production of DHEA decrease in activity (adrenopause) without clinically evident changes in corticotropin $(\mathrm{ACTH})$ and cortisol secretion. A central pacemaker in the hypothalamus or higher brain areas (or both) is hypothesized, which together with changes in the peripheral organs (the ovaries, testicles, and adrenal cortex) regulate the aging process of these endocrine axes.

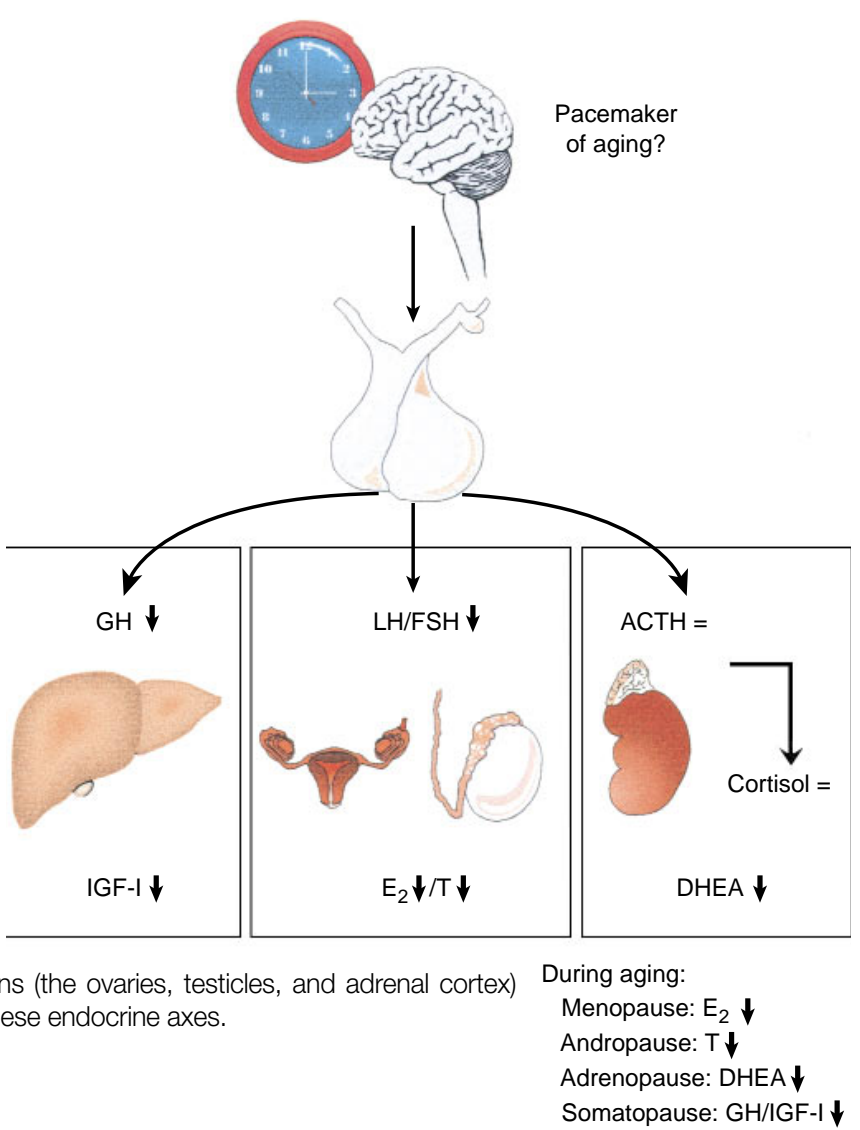


and in their secretory capacity, as well as by an age-related decrease in episodic and stimulated gonadotropin secretion (25).

The second hormonal system demonstrating age-related changes is the circulating levels of dehydroepiandrosterone (DHEA) and its sulphate (DHEAS), which gradually decline with age, resulting in "adrenopause" $(26,27)$. Adrenal secretion of DHEA gradually decreases over time, whereas adrenocorticotropin (ACTH) secretion, which is physiologically linked to plasma cortisol levels, remains largely unchanged. The decline in DHEA(S) levels in both sexes contrasts therefore with the maintenance of plasma cortisol levels and seems to be caused by a selective decrease in the number of functional zona reticularis cells in the adrenal cortex rather than regulated by a central (hypothalamic) pacemaker of aging (27).

The third endocrine system that gradually declines in activity during aging is the growth hormone $(\mathrm{GH}) /$ insulin-like growth factor I (IGF-I) axis (Fig. 2) (5, 28). Mean pulse amplitude, duration, and fraction of $\mathrm{GH}$ secreted, but not pulse frequency, gradually decrease during aging. In parallel, there is a progressive fall in circulating IGF-I levels in both sexes (28). There is no evidence for a "peripheral" factor in this process of "somatopause," and its triggering pacemaker seems mainly localized in the hypothalamus, because pituitary somatotrops, even of the oldest old, can be restored to their youthful secretory capacity during treatment with GH-releasing peptides.

We do not know whether the changes in gonadal function (menopause and andropause) are interrelated with the processes of adrenopause and somatopause, which occur in both sexes. In addition, functional correlates (such as muscle size and function, fat and bone mass, progression of atherosclerosis, and changes in cognitive function) have not been related to these changes in endocrine activity. However, a number of effects of normal aging closely resemble features of (isolated) hormonal deficiency (such as hypogonadism and $\mathrm{GH}$ deficiency), which in mid-adult patients are successfully reversed by replacement therapy with the appropriate hormone (29). Although aging does not simply result from a variety of hormone deficiency states, medical intervention in the processes of meno-, andro-, adreno-, or somatopause might successfully prevent or delay some aspects of the aging process.
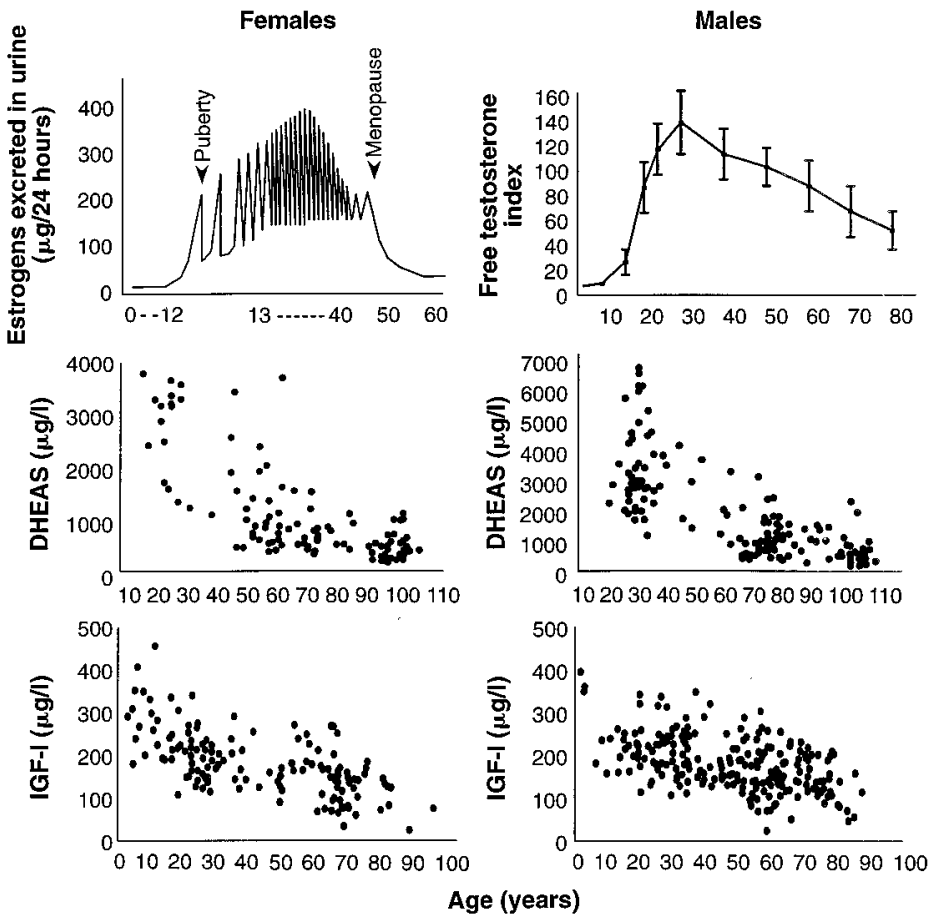

Fig. 3. Changes occurring in the hormone levels of normal women (left) and men (right) during the aging process. Estrogen secretion throughout an individual normal woman's life (expressed as urinary estrogen excretion) is shown at the top left [after (22)], and the mean free T index (the ratio of serum total T to sex hormone-binding globulin levels) during the lifespan of healthy men is shown at the top right. In the middle panels, serum DHEAS concentrations in 114 healthy women (left) and 163 healthy men (right) are shown [adapted from (26)]. In the lower panel, the course of serum IGF-I concentrations in 131 healthy women (left) and 223 healthy men (right) during aging is shown [adapted from (28)]. Note the difference in the distribution of ages in the different panels.

\section{Menopause and Andropause}

In most women, this period of decline in estrogens is accompanied by vasomotor reactions, depressed mood, and changes in skin and body composition (increase in body fat and decrease in muscle mass). In the subsequent years, the loss of estrogens is followed by a high incidence of cardiovascular disease, loss of bone mass, and cognitive impairment (Fig. 3) (30). The average age of menopause (51.4 years) has not changed over time and seems to be largely determined by genetic factors. Because life expectancy is increasing, the time a woman spends after menopause constitutes more than one third of her life. Long-term (5 to 10 years) hormone replacement with estrogens in combination with progestins starting at menopause has many advantages (31). Apart from relieving hot flashes and mood changes, reducing skin and reproductive tract atrophy (such as dryness of the vagina and urinary incontinence), and preventing changes in body composition, estrogen/progestin replacement therapy delays atherosclerosis, loss of bone mass, and loss of cognitive function. Life expectancy seems not to be influenced by estrogen/progestin replacement, but atherosclerosis and bone loss are considerably delayed (Table 1) (31). An exciting observation is the apparent delay in the onset of Alzheimer's disease in women treated with hormone replacement (32). The mechanisms of these estrogen effects on the aging brain are speculative at present (33).

There are, however, also important negative effects of estrogen/progestin replacement therapy during menopause. The most compelling problem is the increased incidence of breast cancer (Table 1) (34). Little data are available on the effects of a yearly mammogram on morbidity and mortality of breast cancer patients diagnosed during or after hormone replacement therapy. In addition, the inconvenience of irregular menstruations has an effect on long-term compliance with this treatment. ["Nonbleeding" estrogen/progestins have recently been developed, however (35)]. At present, the decision to start hormone replacement at menopause should be based on the individual's risk factors, her attitude toward hormonal treatment, and knowledge of its risks and benefits. Knowledge and education influence this decision; in a recent Swedish study, only $24 \%$ of women aged 54 years but $72 \%$ of female general practitioners and $88 \%$ of female gynecologists were on estrogen/progestin replacement therapy (36).

A new development in the search for optimalizing hormone replacement therapy during menopause came from observations 
that tamoxifen has variable anti- and estrogenic actions in different tissues (37). Tamoxifen suppresses the growth of estrogen receptor-positive breast cancer cells. Longterm treatment of menopausal breast cancer patients with tamoxifen also lowered the incidence of new (contralateral) breast cancers by $40 \%$ : In addition, the number of cardiovascular incidents decreased by $70 \%$, and the age-related decrease in bone mineral density was partially prevented (38). These initially puzzling observations were explained by the fact that tamoxifen, and other compounds such as raloxifene, have estrogen receptor-modulating effects, exerting anti-estrogenic actions on normal and cancerous breast tissue but agonistic actions on bone, lipids, and the blood vessel walls (39). These effects of tamoxifen and raloxifene may be explained by differential stabilization of the conformations of the estrogen receptor, but might also relate to the activation of different estrogen receptor forms, in which the $\alpha$ form is the "classical" estrogen receptor, whereas a $\beta$ form mediates the vascular and bone effects of estrogens (40). It remains to be seen whether compounds such as raloxifene have clinically important beneficial effects on bone density, the vascular wall, and the brain, as well as inhibition of the development of breast cancer without inducing endometrium hyperplasia.

Age-associated changes in T levels occur slowly and subtly (Fig. 3). More than 60\% of healthy elderly men over 65 years of age have free $\mathrm{T}$ levels below the normal values of men aged 30 to 35 (41). The variability in circulating (free) $\mathrm{T}$ levels among elderly men is considerable, however. Numerous studies of large populations of healthy men have shown a marked rise in the incidence of impotence to over $50 \%$ in men aged 60 to $70(42)$. Although this increase in impotence seems to occur in the same age group that shows a clear decline in free $\mathrm{T}$ levels, no causal relationships have been demonstrated. Testosterone replacement therapy is in most instances not effective for the treatment of impotence in elderly males; other factors such as atherosclerosis, alcohol consumption, smoking, and the quality of personal relationships seem to be more important denominators (43).

Testosterone has long been known for its anabolic effects (44). It is unknown, however, whether the age-related decline in muscle mass and muscle strength is causatively related to the parallel decrease in free T levels. Muscle weakness, anemia, lowered bone mass, and mood disturbances rapidly normalize in mid-adult hypogonadal men during $\mathrm{T}$ replacement therapy (44). In addition, treatment of eugonadal adult men with pharmacological doses of $\mathrm{T}$ increases muscle mass and strength, especially in combination with exercise or weight training (45). Very few long-term, placebo-controlled studies on $\mathrm{T}$ replacement in the frail elderly have been reported. The data available point to a positive effect on muscle mass and strength, as well as on cognition and the sense of wellbeing (46). An increase in hematocrit and in the number of red blood cells, as well as a slightly unfavorably effect on lipid profiles, have also been reported during $\mathrm{T}$ treatment (46). T replacement therapy in elderly men is limited in its use, however, because of its unpredictable effects on the size of the prostate. Although some studies report no effects on circulating prostatespecific antigen (PSA) levels, prostate volume, or symptoms of urinary outlet ob-

Table 1. Lifetime probabilities of disease occurrence for a 50-year-old white woman treated with long-term hormone replacement [from a meta-analysis by Grady et al. (32)]. $\mathrm{E}_{2}+\mathrm{P}=$ estrogen plus progestin. The estimated lifetime probabilities of developing the conditions mentioned have been derived from mortality and incidence data from the 1987 Vital Statistics of the United States and other sources mentioned in appendix 2 of (32). The relative risks are the "best" estimates of the relative risk for developing each condition in long-term hormone users as compared with nonusers. These estimates were derived from a model of the risks and benefits of hormone therapy developed by Grady et al. (32). A number of limitations and assumptions have to be taken into consideration when interpreting this table: The duration of the use and dose regimens of $E_{2}+P$ varied considerably between studies included in the meta-analysis (duration ranged from 2 to 10 years). It was assumed that the addition of progestin to the estrogen regimen would increase the risk of breast cancer from 1.25 to 2.0.

\begin{tabular}{lccc}
\hline \multirow{2}{*}{\multicolumn{1}{c}{ Condition }} & \multicolumn{2}{c}{ Lifetime probability (\%) } & Relative risk \\
\cline { 2 - 3 } & No treatment & $\mathrm{E}_{2}+\mathrm{P}$ & \\
\hline Coronary heart disease & 46.1 & $13.7^{\star \star}-34.4$ & $0.04^{\star \star}-0.65$ \\
Stroke & 19.8 & 19.3 & 0.96 \\
Hip fracture & 15.3 & 12.0 & 0.75 \\
Alzheimer's disease* & 16.3 & 5.8 & 0.40 \\
Breast cancer & 10.2 & $13.0-19.7$ & $1.25-2.00$ \\
Endometrial cancer & 2.6 & 2.6 & 1.00 \\
Life expectancy (years) & 82.8 & 83.8 & \\
\hline
\end{tabular}

*Adapted according to Tang (34).

${ }^{\star \star}$ Adapted according to Grodstein (65).

struction, a modest irreversible increase in PSA levels has also been observed during $\mathrm{T}$ administration (46). No firm data are available at present concerning a growthstimulatory effect of $\mathrm{T}$ on in situ prostatic cancerous lesions, which frequently occur in elderly men.

Few studies are available on the effects of $\mathrm{T}$ replacement therapy in the elderly. Dose, duration of treatment, the identification of elderly men who might benefit most, risks to the prostate, and possible effects on the process of atherosclerosis remain subjects for study. The concept of developing androgenic compounds with variable biological actions in different organs (antiandrogenic in the prostate) is currently being pursued, but the selection of aging men with clinically important and well-defined hypogonadism remains difficult, a situation that contrasts sharply with abrupt menopause in women.

\section{Adrenopause}

Circulating DHEAS levels in healthy adults are more than 10 times higher than those of cortisol (26). Animal studies in rodents, which have very low circulating DHEAS levels, suggest that DHEA administration prevents obesity, diabetes mellitus, cancer, and heart disease, while enhancing immune function (27). These results suggest that DHEA prolongs lifespan and might be an "elixir of youth." Supportive data in humans are few and highly controversial. Higher DHEAS levels are accompanied by a modestly reduced risk of death from cardiovascular disease in males (47). Functional parameters of activities of daily living in males over 90 years old were lowest in those with the lowest DHEAS levels (26). At age 30, DHEAS levels are approximately five times higher than at age 85 (Fig. 3) (26). DHEA is a universal precursor for androgenic and estrogenic steroid formation in peripheral tissues, which contain a number of DHEA-metabolizing enzymes (27).

Two randomized placebo-controlled studies support the concept that oral administration of DHEA has beneficial effects (48). Three months of daily treatment with $50 \mathrm{mg}$ of DHEA of 20 adults, most of whom were nonelderly individuals (40 to 70 years old), increased DHEA(S) levels to young adult levels, increased plasma androgen and IGF-I concentrations, and induced a remarkable increase in perceived physical and psychological well-being in both sexes without an effect on libido (48). In a subsequent study, treatment with $100 \mathrm{mg}$ of DHEA for 6 months in eight men and eight women increased lean body mass in both sexes but 
increased muscle strength in the men only (38).

It is unknown whether the increase in sex steroid levels induced by DHEA is safe with regard to the development of ovarian, prostate, or other types of cancer. DHEA is currently widely used in the United States as a "treatment for aging." With the scientific verdict still out, without confirmation of DHEA's reported beneficial actions in humans, and without a better understanding of its potential risks, it is premature to recommend the routine use of DHEA for delaying or preventing the physiologic consequences of aging (49).

\section{Somatopause}

Little is known concerning the biological consequences of somatopause (50). In several studies of healthy individuals of a broad age range, an association was observed between the maximum aerobic capacity and circulating IGF-I levels (51). The expectation that somatopause contributes to the decline of functional capacity in the elderly is mainly derived from studies in which GH replacement therapy of GH-deficient adults was shown to increase muscle mass, muscle strength, bone mass, and the quality of life. A beneficial effect on the lipid profile and an important decrease in fat mass were also observed in such patients (52). As in hypogonadal individuals, adult $\mathrm{GH}$ deficiency is considered a model of normal aging, because a number of catabolic processes that are central in the biology of aging can be reversed by GH administration.

GH administration for 3 to 6 months to healthy elderly individuals increased IGF-I levels to those observed in control individuals half their age, while muscle mass, skin thickness, and bone mineral content significantly increased and fat mass decreased (53). A disappointing aspect of the studies is that no positive effect of $\mathrm{GH}$ therapy was observed on muscle strength and maximal oxygen consumption (54). If $\mathrm{GH}$ was administered in combination with resistance exercise training, however, a significant positive effect on muscle mass and muscle strength was recorded that did not differ from that seen with placebo treatment, which suggests that $\mathrm{GH}$ does not add to the beneficial effects of exercise (55).

Earlier studies have demonstrated that pharmacological doses of $\mathrm{GH}$ prevent the "auto-cannibalistic" effects of acute diseases on muscle mass (56). This prompted us to carry out a randomized placebo-controlled trial of 6 weeks of $\mathrm{GH}$ administration in elderly individuals with an acute hip fracture. Our preliminary results indicate that in individuals over 75 years old, $\mathrm{GH}$ admin- istration causes a statistically significant earlier return to independent living after the fracture. Comparable studies are currently being done in several countries, and confirmation is needed before $\mathrm{GH}$ might gain a place in the treatment of acute catabolic states in the frail elderly.

Other components in the regulation of the GH/IGF-I axis are effective in activating GH and IGF-I secretion. Long-acting derivatives of the hypothalamic peptide growth hormone releasing hormone (GHRH), given twice daily subcutaneously for 14 days to healthy men 70 years old, increased GH and IGF-I levels to those encountered in 35-year-olds (57). These studies support the concept that somatopause is primarily hypothalamically driven and that pituitary somatotrops retain their capacity to synthesize and secrete high levels of $\mathrm{GH}$. GH releasing peptides (GHRPs) are oligopeptides with even more powerful GH-releasing effects (58). Originally developed by design, it has recently been suggested that they mediate their GH-secretory effects through endogenous specific receptors (59). Nonpeptide analogs such as MK677 and L-692,429 have powerful GH-releasing effects, restoring IGF-I secretion in the elderly to levels encountered in young adults (60). Long-term oral administration of MK-677 to healthy elderly individuals increased lean body mass but not muscle strength. If proven to be $\mathrm{GH}$-specific, these orally active GHRP derivatives might be important alternatives to subcutaneously administered GH in the reversal of somatopause, in the prevention of frailty, and in the reversal of acute catabolism. The longterm safety of the activation of GH/IGF-I levels remains uncertain with regard to tumor growth, as most human solid cancers express IGF-I receptors (60).

\section{The Concept of Successful Aging}

There is considerable variation in the effects of aging on healthy individuals, with some persons exhibiting extensive alteration in physiological functions with age and others little or none. It has been suggested that it might be useful to distinguish between usual and successful patterns of aging (61). Genetic factors, lifestyle, and societal investments in a safe and healthful environment are important aspects of successful aging (62). Traditionally, the aging process, including the development of physical frailty toward the end of life, has been considered to be physiological and unavoidable. In recent years, however, it has become evident that it might not be necessary to accept the grim stereotype of aging as an unalterable process of decline and loss $(9,61)$. As life expectancy increases further in coming decades, the overarching goal for the year 2000 and thereafter should be "an increase in years of healthy life with a full range of functional capacity at each stage of life" (63). Such a compression of morbidity can often be achieved through lifestyle measures, but a number of aspects of the aging process of the endocrine system invite the development of "routine" medical intervention programs offering long-term replacement therapy with one or more hormones, in order to delay the aging process and to allow us to live for a longer period in a relatively intact state.

\section{REFERENCES AND NOTES}

1. J. F. Fries, N. Engl. J. Med. 303, 130 (1980).

2. E. W. Campion, ibid. 330, 1819 (1994).

3. M. R. Kosorok, G. S. Omenn, P. Diehr, T. D. Koepsell, D. L. Patrick, Am. J. Public Health 82, 1263 (1992).

4. A. J. Moss and V. L. Parsons, Current Estimates from the National Health Interview Survey: United States, 1985 (National Center for Health Statistics, Hyattsville, MD, 1986; Vital and Health Statistics, series 10, no. 160, Department of Health and Human Services publication PHS 86-1588); J. A. Brody, Nature 315 463 (1985).

5. D. Rudman and U. M. P. Rao, in Endocrinology and Metabolism in the Elderly, J. E. Morley and S. G. Koverman, Eds. (Blackwell Scientific, Oxford, UK, 1992), pp. 50-68.

6. D. M. Buchner and E. H. Wagner, Clin. Geriatr. Med. 7, 1 (1992).

7. M. E. Tinetti, M. Spechley, S. F. Ginter, N. Engl. J. Med. 319, 1701 (1988); D. Prudham and J. G. Evans, Age Ageing 10, 141 (1981); M. E. Tinetti, J. Am. Geriatr. Soc. 35, 644 (1987)

8. D. A. Kallman, C. C. Plato, J. D. Tobin, J. Gerontol. 45, M82 (1990).

9. M. A. Fiatarone et al., N. Engl. J. Med. 330, 1769 (1994).

10. J. M. Guralnik, L. Ferrucci, E. M. Simonsick, M. E. Salive, R. B. Wallace, ibid. 332, 556 (1995).

11. W. Rakowski and V. Mor, J. Gerontol. 47, M122 (1992).

12. S. G. Korenman, Endocrine Aspects of Aging (Elsevier, New York, 1982)

13. K. L. Minaker, Diabetes Care 13 (suppl. 2), 34 (1990).

14. M. I. Harris, Clin. Geriatr. Med. 6, 703 (1990).

15. A. L. Peters and M. B. Davidson, in Internal Textbook of Diabetes Mellitus, K. G. M. M. Alberti, P. Zimmet, R. A. DeFronzo, Eds. (Wiley, Chichester, UK, 1997), pp. 1151-1183.

16. M. B. Davidson, Metabolism 28, 688 (1979).

17. R. I. Fink, O. G. Kolterman, J. M. Olefsky, J. Gerontol. 39, 273 (1984).

18. S. Mariotti, C. Franceschi, A. Cossarizza, A. Pinchera, Endocr. Rev. 16, 686 (1995).

19. W. Hijmans, J. Radl, G. F. Bottazzo, D. Doniach, Mech. Ageing Dev. 26, 83 (1984).

20. S. Mariotti et al., Lancet 339, 1506 (1992).

21. H. A. Rubenstein, V. P. J. Butler, S. C. Werner, J. Clin. Endocrinol. Metab. 37, 247 (1973).

22. A. C. Guyton, in Textbook of Medical Physiology, A. C. Guyton, Ed. (Saunders, Philadelphia, ed. 8, 1991), pp. 899-914.

23. P. M. Wise, K. M. Krajnak, M. L. Kashon, Science 273, 67 (1996).

24. A. Vermeulen, J. Clin. Endocrinol. Metab. 73, 221 (1991).

25. S. M. Harman and P. D. Tsitouras, ibid. 51, 35 (1980). S. M. Harman et al., ibid. 54, 547 (1982)

26. G. Ravaglia et al., J. Clin. Endocrinol. Metab. 81 1173 (1996).

27. J. Herbert, Lancet 345, 1193 (1995); F. Labrie, A. Belanger, J. Simard, V. Luu-The, C. Labrie, Ann. N. Y. Acad. Sci. 774, 16 (1995); P. J. Hornsby, ibid., p. 29.

28. E. Corpas, M. Harman, M. R. Blackman, Endocr. 
Rev. 14, 20 (1993).

29. M. R. Blackman, Endocrinol. Metab. Clin. North. Am. 16, 981 (1987).

30. R. Lindsay, T. L. Bush, D. Grady, L. Speroff, R. A Lobo, J. Clin. Endocrinol. Metab. 81, 3829 (1996).

31. D. Grady et al., Ann. Intern. Med. 117, 1016 (1992).

32. M. X. Tang et al., Lancet 348, 429 (1996).

33. A. Burns and D. Murphy, ibid., p. 420.

34. G. A. Colditz et al., N. Engl. J. Med. 332, 1589 (1995); D. Grady and V. Ernster, Am. J. Epidemiol. 134, 1396 (1991)

35. A. T. Leather and J. W. W. Studd, Br. J. Obstet. Gynaecol. 97, 1071 (1990).

36. K. Andersson, L.-A. Mattson, I. Milsom, Lancet $\mathbf{3 4 8}$ 1521 (1996)

37. R. J. Santen, J. Clin. Endocrinol. Metab. 81, 2027 (1996); D. J. Grainger and J. C. Metcalfe, Nature Med. 2, 381 (1996).

38. Early Breast Cancer Triallists' Collaborative Group, Lancet 339, 1 (1992); R. R. Love et al., N. Engl. J. Med. 326, 852 (1992); L. E. Rutqvist and A. Mattson, J. Natl. Cancer Inst. 85, 1398 (1993); A. B. Grey et al., Am. J. Med. 99, 636 (1995).

39. N. N. Yang et al., Endocrinology 137, 2075 (1996); L. J. Black et al., J. Clin. Invest. 93, 63 (1994); M. W. Draper et al., J. Bone Miner. Res. 11, 835 (1996).

40. D. P. McDonnell, D. L. Clemm, T. Hermann, M. E. Goldman, J. W. Pike, Mol. Endocrinol. 9, 659 (1995); K. S. Korach, Recent Prog. Horm. Res. 51, 159 (1996).

41. J. S. Tenover, Endocrinol. Metab. Clin. North Am. 23, 877 (1994)

42. C. K. Pearlman and L. I. Kobashi, J. Urol. 107, 298 (1972).
43. S. Bhasin and W. J. Bremner, J. Clin. Endocrinol. Metab. 82, 3 (1997); C. J. Bagatell and W. J. Bremner, N. Engl. J. Med. 334, 707 (1996).

44. I. G. Brodsky, P. Balagopal, K. Sreekumaran Nair, J. Clin. Endocrinol. Metab. 81, 3469 (1996). C. Wang et al., ibid., p. 3654.

45. S. Bhasin et al., N. Engl. J. Med. 335, 1 (1996).

46. J. S. Tenover, J. Clin. Endocrinol. Metab. 75, 1092 (1992); C. Wang et al., ibid. 81, 3578 (1996).

47. E. Barrett-Connor and D. Goodman-Gruen, Ann. N. Y. Acad. Sci. 774, 259 (1995)

48. E. E. Baulieu, C.R. Acad. Sci. Paris Sci. Vie 318, 7 (1995); A. J. Morales, J. J. Nolan, J. C. Nelson, S. S. C. Yen, J. Clin. Endocrinol. Metab. 78, 1360 (1994); S. S. C. Yen, A. J. Morales, O. Khorram, Ann. N. Y. Acad. Sci. 774, 128 (1995)

49. J. E. Nestler, Ann. N. Y. Acad. Sci. 774, ix (1995); A Skolnick, J. Am. Med. Assoc. 276, 1365 (1996)

50. D. Rudman, J. Am. Geriatr. Soc. 33, 800 (1984); S. E. Borst, W. J. Millard, D. T. Lowenthal, ibid. 42 528 (1994). A. A. Toogood, P. A. O'Neill, S. M. Shalet, J. Clin. Endocrinol. Metab. 81, 460 (1996).

51. E. T. Poehlman and K. C. Copeland, J. Clin. Endocrinol. Metab. 71, 1468 (1990); M. A. Papadakis et al., J. Am. Geriatr. Soc. 43, 1350 (1995).

52. F Salomon, R C Cuneao, R. Hesp, P. H Sonksen, N. Engl. J. Med. 321, 1797 (1989); R. Nass et al., J. Clin. Endocrinol. Metab. 80, 552 (1995); A. F. Attanasio, ibid. 82, 82 (1997).

53. D. Rudman et al., N. Engl. J. Med. 323, 1 (1990)

54. M. A. Papadakis et al., Ann. Intern. Med. 124, 708 (1996).

55. D. R. Taaffe et al., Clin. Endocrinol. Metab. 79, 1361
(1994); K. E. Yarasheski, J. J. Zachwieja, J. A. Campbell, D. M. Bier, Am. J. Physiol. 268, E268 (1995).

56. R. Von Kries, Br. Med J 303, 1147 (1991); Z M. Jiang et al. , Ann. Surg. 210, 513 (1989); D. N. Herndon et al., ibid. 212, 424 (1990); D. Waters et al., Ann. Intern. Med. 125, 865 (1996).

57. E. Corpas, S. M. Harman, M. A. Pineyro, R. Roberson, M. R. Blackman, J. Clin. Endocrinol. Metab. 75 , 530 (1992)

58. C. Y. Bowers, F. A. Momany, G. A. Reynolds, A. Hong, Endocrinology 114, 1537 (1984); P. Saenger, J. Clin. Endocrinol. Metab. 81, 2773 (1996); M. Korbonits and A. B. Grossman, Trends Endocrinol. Metab. 6, 43 (1995).

59. S. S. Pongs et al., Mol. Endocrinol. 10, 57 (1996); A. D. Howard et al., Science 273, 974 (1996).

60. V. A. Blakesley, B. S. Stannard, T. Kalebic, L. J. Helman, D. LeRoith, J. Endocrinol. 152, 339 (1997); I. M. Chapman et al., J. Clin. Endocrinol. Metab. 81, 4249 (1996); I. M. Chapman, M. L. Hartman, S. S. Pezzoli, M. O. Thorner, ibid., p. 2874.

61. J. W. Rowe and R. L. Kahn, Science 237, 143 (1987).

62. W. R. Hazzard, J. Am. Med. Assoc. 247, 1964 (1995).

63. Healthy People 2000: National and Health Promotion and Disease Prevention Objectives (U.S. Government Printing Office, Washington, DC, 1991).

64. C. V. Hsich and R. B. Philips, J. Manipulative Physiol. Ther. 13, 72 (1990)

65. F. Grodstein et al., N. Engl. J. Med. 335, 453 (1996).

\section{Editor for Books and New Media}

SCiENCE seeks a resourceful editor to help redefine our book review section. We will extend the scope of our existing book reviews of the major publications in science to include software, CD-ROM titles, and other new media. The applicant will commission and edit reviews from experts in all fields. A genuine broad interest in science necessary and a flair for editing solicited work into concise, vigorous prose preferred. In addition, the editor will occasionally write some of the shorter reviews. Applicant should have a degree in a scientific field, M.S. or Ph.D. preferred.

\section{Please send CV to:}

The American Association for the Advancement of Science BRE-\#1212, Human Resources Department 1200 New York Avenue, Suite 100 Washington DC 20005 EOE. Non-smoking work environment

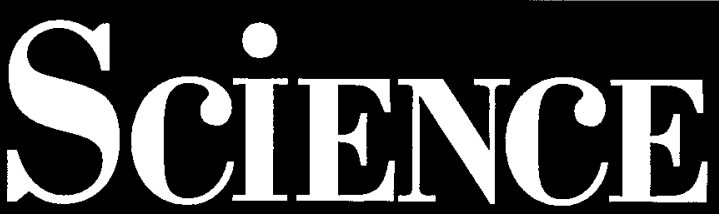

http://www.sciencemag.org

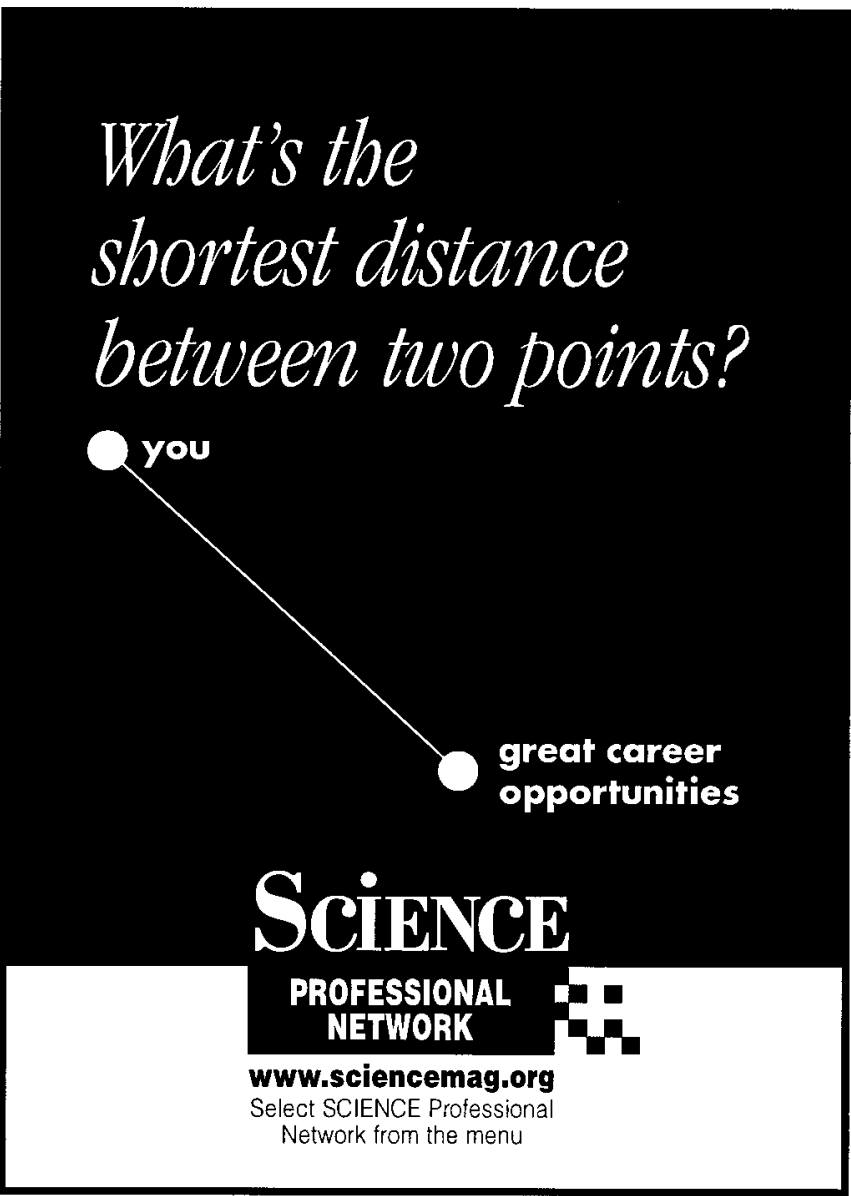


If you wish to distribute this article to others, you can order high-quality copies for your colleagues, clients, or customers by clicking here.

Permission to republish or repurpose articles or portions of articles can be obtained by following the guidelines here.

The following resources related to this article are available online at www.sciencemag.org (this information is current as of August 19, 2015 ):

Updated information and services, including high-resolution figures, can be found in the online version of this article at:

http://www.sciencemag.org/content/278/5337/419.full.html

This article cites 83 articles, 11 of which can be accessed free:

http://www.sciencemag.org/content/278/5337/419.full.html\#ref-list-1

This article has been cited by 413 article(s) on the ISI Web of Science

This article has been cited by 88 articles hosted by HighWire Press; see:

http://www.sciencemag.org/content/278/5337/419.full.html\#related-urls

This article appears in the following subject collections:

Medicine, Diseases

http://www.sciencemag.org/cgi/collection/medicine 